tropical medicine, but $I$ do wish to suggest, in the light of my long Indian experience, that the time has come for the further advance I have indicated. Indeed, I think this has been necessitated by the very success of recent researches in this field, including all the work done on dysenteries during the war, for now so many of the simpleryproblems have been solved the remaining problems of tropical medicine will require much more prolonged and detailed inquiries, including team work, such as is being provided for in the Calcutta school, the liberal public supportw of which would serve as a stimulating example to London philanthropists, and especially to those whose firms or companies trade with tropical countries. Their young assistants have to live in such climates exposed to unnecessary dangers to their health from the lack of the safeguards provided by research laboratories, and I appeal to their employers for support for the proposals I have ventured to bring forward.

\section{PREVENTION OF VENEREAL DISEASE.}

$A T$ a conference on the prevention of venereal disease, under the chairmanship of Lord AskwITH, on March 1st, Dr. MEARns FraSER, M.O.H. for Portsmouth, proposed :

"That. in view of the terrible effects of venereal diseases on the health of the nation, and especially because of their effects upcn women and children, there is urgent need for health authorities to institute active measures to protect the inhabitants of their districts against these diseases. venereal diseases, as to the manner in which they are spres and. above all, education in the methods of immediate selfdisinfection, by which venereal diseases can be largely prevented."

He said that the Society for the Prevention of Venereal Disease was anxious to induce local authorities to make known the methods of self-disinfection to the public. He considered the time! was ripe for local authorities to take considered the time! was ripe for local authorities to take action on the lines adopted by Portsmouth. Mhe resolution was seconded by Dr. CHARLES SAUNDERS, M.O.H. For West Ham, who said that there were resolutions on the minutes of people in immediate self-disinfection.

Dr. E. W. HOPE, M.O.H. for Liverpool, stated that he was heartily in accord with the views expressed by Dr. Fraser, and gathered that, when emphasizing this aspect of the question, other aspects would not be lost sight of. He thought that those who raised objections from the moral standpoint seemed to forget that no obstacles were being placed in their way.

The MAYOR oF PORTSMOUTH said that the inhabitants of Portsmouth had all now come round to-Dr. Fraser's way of thinking, and he had had all the support which any medical officer of health could wish for on this subject.

Dr. BoND, M.O.H. for Holborn, said that Holborn was the first London borough which had adopted the method advocated first London borough which had adopted the method advocated sidered this method of education exceedingly simple and very sidered this method of education exceedingly simple and very inexpensive. Dr. HoLroyD, M. . H. for Chatham, said that when he brought the question of education and immediate selfdisinfection before his Health Committee it was unanimously were any dissentient opinions expressed in the town.

Mr. ThoMrpson. Chairman of the Health Committee, Liver poo' said that during the past year they had bad 78,000 attendances ai the Liyerpool venereal clinics, and emphasized the necessity for continuity of treatment. Mr. WHITWORTH, Chairman of the Bedfordshire Venereal Committee, considered it necessary to amend the Venereal Disease Act, 1917, so as to enable anyone to go to a chemist and ask for what ho
wanted.

The resolution was supported also by Dr. J. B. HoweLL, 作 Croydon.

The Chairman then submitted the following addendum to the resolution :

"Resolved further that this resolution and opinion be forwarded to health authorities throughout the United Kingdom, with the

With this addition the resolution was then put to the meeting and carried unanimously.

Lord WILLOŨGHBY DE BRoKe, President of the Society for the Prevention of Venereal Disease, moved a vote of thanks to Lord and Lady Askwith. Dr. WANSEY BAYLY, the Honorary Secretary, who seconded, said that he had just received a telegram from Dr. J. Priestley, M.O.H. for Lambeth, ex pressing cordial support of the resolution, and that Colonel Officers of Health, had intended to be present, unless prevented by parliamentary duties.

Owang to the increase of poverty in Austria, an insurance society has been founded at Vienna for members of the middle classes under the name of the "Yellow Cross." Those insured have the right to choose their doctor, and in operation cases their surgeon, as well as their hospital or nursing home.

\section{MOTOR NOTES FOR MEDICAL MEN. BY H. MASSAC BUIST.}

Ministerial and Commercial Aspects.

IT is not good news that the Ministry of Transport, which has scarcely been got into working order, is to lose its head, Sir Eric Geddes, next summer. Vhether the Ministry itself is to lapse is apparently still undecided. In all likelihood its functions will be absorbed by one of the older ministries. This at least is certain, that once a Government has regarded the question of internal transport as a national affair it will not be allowed to revert to the condition in which it was the sport of local authorities. All that motor owners and builders can doin the meantime is to be forewarned that a very sharp look-out will have to be kept on the money raised from them by way of taxation. Unless we see to it very carefully an increasing portion of the net sum raised from motor taxes will begin to be diverted to other ends. Already there are signs that at no distant date the bulk of the motorists money spent on the roads will not be employed to give us twentieth-century highways and byways for twentieth-century traffic, but merely to patch up and keep going obsolete systems; in other words, to pursue the work of maintaining unsuitable road types which, among other things, are enormously wasteful when employed for latter-day traffic. In the current year far too small a proportion of the money is being spent on that work of permanent road improvement which should be the main objective of all endeavour. There are indications that that work may be so limited in ultimate scope that, in relatively a few years, all that will be held necessary will have been accomplished in that connexion; apparently the idea is that the total amount of funds then supplied yearly by motorists by way of taxation will be employed solely for maintaining the highways and not to remodel them. This should not be allowed. Among the points that concern motorists and are under consideration by the Government at the moment, is the question of the left-side drive. It has been condemned by many coroners throughout the country as being dangerous. It cannot be said that anything has happened this year which has not tended to confirm that danger, rarticularly as : concerns the use of left-side driven vehicles wherein the driver is enclosed by coverad coach. work. The draft of the" promis zd new bill to deal with speed on the higlroads and so on will either undergo modification before introduction to the House, or it will prove a very unpopular measure there.

\section{Prices.}

The first motoring development of the year has been the inevitable and long-expected campaign of price-cutting, chiefly on the part of those who have produced car types which are little better than furbished up pre-war models. This move has been countered by those who produce cars for which there is a demand. Such firms have given undertakings to the effect that, should there be any fall in the price of their vehicles as between now and June or July, as the case may be, any buyers placing orders to-day will receive a rebate of any such difference in price. But it must be understood clearly that it is impossible for the cars which are in most demand to be sold at lower prices than are ruling. Already the price of many of them is too low from the point of view of the accountants of the manufacturers. Moreover, where genuine post-war designs are carried out with post.war material and by post war manufacturing methods it is not possible to reduce prices, though these may appear dear. The reason is that such designs call for very expensive methods of production with the view to making motoring more economical. This was admirably illustrated last week when Vickers' inotór manufacturing concern, the Wolseley Company, invited the Press to inspect its works after an interval of seven years. During that period the original shops at Adderley Park, Birming ham, have been expanded to a floor space of thirty-three acres, and entirely new works for the production of the 10-h.p. four-cylinder, overhead valve engined, three speed Wolseley (ex.Stellite) car have been set up"with a floor space of sixty-six acres at Ward End, a couple of miles away from the parent shops. Though at the first glance the machines are apparently not cheap, a consideration of 
the quality and features embodied in them reveals that they can compare farourably with the cheapest home or foreign-produced vehicle under the heading of bare cost at the end of two years. 'Pliat is to say, real post-war lesigning ensures a big economy in running and main. tenance costs.

\section{Real Motoring Economy.}

In the case of the 10.h.p. car the tax is abont $£ 11$ a year, yet each engine bas to pass a bench test of $24-25 \mathrm{~h}$. p., and with such a vehicle it is possible, without ever exceeding forty miles an bour, to average thirty-two miles an hoar from point to point in long runs when driving in $\operatorname{an}$ ordinarily cautious way and without "hunting" the car. These ongines axe guaranteed to give thirty miles to the gallon of fuel, and I make bold to foretell that within six weeks the cars will be selling with a guarantee that the engine will accomplish forty miles to the gallon. Thens the owner saves both in petrel, which is costly, and in engine tax, which is a sabstitute for the petrol tax obtaining last year. How this is done may be illustrated by taking the mean effective pressure of this engine compared with the average of standardized type. The mean effective pres. sure means the motor fuel supplied to the engine and turned into horse-power. In the case of the popular American type of car a mean effective pressure figure of 78 is about the average, and 85 wonld be a fair figure for most British and Continental standard cars, whereas in the case of the Wolseley post-war engine it is 110, a figure better than was obtained with the former cones specially built for the Touxist. Trophy Races before the war. It is, however, one thing to aim at empleying much better engine-in which connexion the firm has just standardized battery ignition sets for theas types-and quite another matter to ovolve such an entinely now cluassis as shall represent a car which is 100 per cent. postwar design, instead of merely placing a post-wrar typo of engine in a pre-war chassis. The Wolseley coachwork, as well as the chassis, is made on now lines. In this little car the back axle and the engine form in effect the frame of the vehicle. Another point about which the nontechnical are often puzzled is how a machine having quarter elliptic front springs and no racius rods would fare in the event of the main leat of a front spring breaking. A glance at tho construction employed vill reveal that there is a short dummy leaf with an oyelet hole underneath the main spring leaf. This dammy leef does no work when the car is in normal condition. Bnt the eyelet hole of this abbreviated dummy undermost leaf is attached to the shortest and uppermost spring leaf proper by a shackle. Thus it is possible to saw throngh the leaves of the spring-I doubt if they have ever been broken, for they are proportionately strong -and atill drive at forty miles an hour with perfect safety with a ming thus artificially broken. This simple detail is the subject natter of a master patent, a fact of which some rival manufacturers appear to be nnaware, in that they are standardizing this so simple and effective solution of a very difficult engineering problem.

The Scientific Use of Prant.

This car, together with the 15-h.p. $\$ 16 \mathrm{tgx}$ model, the engine of which is tested to give 45 to 46 h.p., is of pqrticular interest to the medical man by reason of the low running costs. The springing system common to both results in a set of tyres being good for at least a year's work under average conditions. The economy, withont sacrifice of the distinctive qualities of rapid acceleration and good hill-climbing, is accounted for mainly by a combination of three factors. The first is the even torque of the engine at all speeds and loads, for these are very highgrade engineering constructions ; the second is the smoothness of the clutch and of the worm drive; and the third, of course, is the exploitation of the special form of springing which is perpetually plangent, and with which it is im. possible to get a jar, the most that can be experienced being a plunge. The wheels follow the contour of the road, so do not jump and spin, with consequent. grinding. 'Throughout the engine and the chassis of both types workmanship to exceedingly close limits is made possible by the war experience, which, in part, is continued by the- Wolseley production of screw gauges, not merely for its own works bat practically for the supply of the entire British industry and for export. Every one of those gauges is made by a girl at a machine a little larger tlian a sewing machine, yet every gauge so produced has tí pass the National Physical Laboratory tests, whieh require it to be accurate to within oue ten thousandth part of an inch in each of seven elements in wlich it is measured photographically. In short, there is here no manufacturing of cars by hand. Every part of the work is sectionized. There are two laboratories on the establishment, for, apart from that. concerned with experimental work, every piece of raw material used is tested. Judged by the pre-war scale of British motor production the experimental department itself would be quite a considerable factory. Practically every make of car in a range between 8 h.p. and 50 h.p. if tested, so that the data obtainod in connexion with it are available in comparative form.

100 per Cent. Efficiency.

The firm does its own stamping. In these vast factories there are made not merely the aluminium, but the stee castings for cylinders, and for every part of a car which is ordinarily bought from outside, including, for example, the back axle details. By the multi-jig principle it is possible to machine a couple of dozen crankshafts in synchronism to the gain of absolute standardization as well as of great economy, because by that means 100 per cent. cutter efficiency is obtained; that is to say, instead of only a twenty-fourth of the total movement, every inch of the travel of the machine under the tool produces cutting. In the huge pressing department approaching completion at a cost of $\$ 120,000$ odd it will be possible to reduce by one. tenth the combined cost of materials and labour for a set of wings for a car. This plant, besides, will press under mans for chassis, body panels, and so fortll. A track assembly system is available when wanted. But the firm has not yet accelerated to full time, though it is turning out 150 cars a week already, for every one of which a retail purchaser has been secured by one of the firm's agents. The delay in the production programme is due to the disastrous effects of the twenty-two weeks moulders' strike, which eost a full years' output, because sinch a dislocation is always of much longer duration than the prime cause of it. The capacity of the Ward End works for turning out the 10-h.p. Wolseley car is 10,000 cars a year. If a night shift is put on in the machine shop, between the two factories it will be possible to turn out, among the three models, 24,000 cars a year; there is 20.h.p. six-cylinder side-valve engined type. The normal day shift production of the two factories is 12,000 cars. The organization is such that output can be accelerated very rapidly now. On the other hand, it is not necessary to accelerate beyond the present output should the Government be able to do nothing in regard to the exchange situation, which is handicapping foreign trade.

The 10-h.p. model is made with a two-seater coupé body as a permanently closed car, which is, nevertheless, airy in warm weather. A two-seater model on the same type of chassis is furnished with Cape cart hood elaborated on such a scheme that, in bad weather, a doctor can make a completely and effectively rainproof motor-carriage of it. The firm announces that there can be no price reduction this year; but it undertakes to prove by figures that its car can compete favourably on combined purchase and ranning cost on a two years' running basis with any vehicles in the market. Of course, at the end of two years a machine made to such very fine limits of materials of such quality would be practically none the worse for wear; whereas the life of most cheap-for-their-size cars is brief. An interesting sidelight is furnished by the fact that one of the largest and foremost engineering houses in Japan has taken out a licence to make these cars, the patent laws of that country rendering that the only means of safeguarding such unique constitutional features.

As illustrating incidentally how closely the prices of the highest classes of small cars are coming to those of the best quality motor bicycle and side-car outfits attention may be drawn to the announcement that the Rover Company has reduced the price of the 8.h.p. twincylinder air-cooled Rover car complete from. $£ 30,0$ to 250 guineas. This is a vehicle with motor cycle scale of tyre upkeep and fuel consumption, yet with the advantages of a car from the points of view of sitting accommodation, protection against the elemerts, thie possession of three forward speeds, worm drive, plate clutch, and plangent quarter elliptic fore and aft springs. 